\title{
Analisis Kualitas Website Universitas Musi Rawas Menggunakan Metode Webqual 4.0
}

\author{
Syafi'ul Hamidani ${ }^{1}$, Darius Antoni ${ }^{2)}$, Afriyudi ${ }^{3)}$ \\ ${ }^{12) 3)}$ Program Magister Teknik Informatika, Universitas Bina Darma \\ Jl. Jenderal Ahmad Yani No.3, 9/10 Ulu Palembang, Kode Pos : 30111 \\ Email : Hamidanipertama@gmail.com ${ }^{1)}$, darius.antoni@binadarma.ac.id ${ }^{2}$, afriyudi@binadarma.ac.id $^{3)}$
}

\begin{abstract}
The Webqual method is one method for testing the quality level of a website based on the perceptions of end users. This method is a development of the Servqual Method that is widely used for measuring service quality. The purpose of this research is to determine the feasibility of the Musi Rawas University website using WebQual 4.0. Structural equation models (SEM) is used as methods and techniques for data analysis. samples in this study as many as 201 people. The data collection technique using questionnaires. Before the questionnaire distributed tested first using validity and reliability test and assessment with the Likert scale. On the validity of the test using the formula Pearson Bevariate while the reliability test using Cronbach's alpha formula. In the assessment using a Likert scale used 5 ratings interval, is Strongly Agree, Agree, Doubt, Disagree and Strongly Disagree. Based on the results of the test of validity views of rhitung > from 0.138 rtabel value then the question is valid. The results of the analysis of the reliability test rhitung > rtabel value of 0.138. From the results of this study concluded that one of the dimensions of WebQual 4.0, namely the quality of information, does not affect user satisfaction significantly. In other words, the manager of the website should give more attention to providing quality information content.
\end{abstract}

Keywords : Webqual, Validity, Reliability

\begin{abstract}
ABSTRAK
Metode Webqual merupakan salah satu metode untuk melakukan pengujian tingkat kualitas website berdasarkan persepsi pengguna akhir, Metode ini merupakan pengembangan dari Metode Servqual yang banyak digunakan untuk pengukuran kualitas jasa. Tujuan dari penelitian ini adalah untuk mengetahui kelayakan website universitas musi rawas dengan menggunakan metode webqual 4.0 dan teknik analisis data menggunakan Structural equation model (SEM). Sampel dalam penelitian ini sebanyak 201 orang mahasiswa. Teknik pengumpulan data dengan menggunakan kuisioner atau angket. Sebelum angket disebarkan diuji terlebih dahulu menggunakan uji validitas dan uji reliabilitas dan penilaian dengan skala likert. Dari hasil penelitian dapat disimpulkan bahwa salah satu dimensi dari WebQual 4.0, yaitu kualitas informasi, tidak mempengaruhi kepuasan pengguna secara signifikan. Dengan kata lain, pengelola website harus memberikan perhatian lebih untuk menyediakan konten informasi yang berkualitas.
\end{abstract}

Kata kunci : Webqual, Validitas, Reliabilitas 


\section{Pendahuluan}

Perkembangan Teknologi Informasi saat ini sudah sangat pesat sehingga sangat sulit untuk mengontrolnya dan bahkan terbilang mustahil. Jarak dan waktu sekarang ini bukan lagi hal yang menjadi masalah, karena adanya bantuan dari teknologi yang ada, hal inilah yang menuntut kebutuhan akan informasi yang lebih cepat, dan akurat, untuk itulah diperlukan suatu metode penyampaian informasi yang mampu memberikan informasi tanpa terhalang jarak dan waktu.

Metode yang tidak memerlukan kontak langsung tentunya akan lebih menghemat waktu dan jarak, karena tidak perlu adanya pertemuan langsung terlebih lagi bila sang penerima informasi berada di luar kota atau jarak yang cukup jauh. Seperti halnya Websites yang dapat memberikan informasi kepada ribuan masyarakat.

Universitas Musi Rawas sebagai Universitas Pertama di kota lubuklinggau dan kabupaten musi rawas, sangat menyadari pentingnya akan kebutuhan mahasiswa dan dosen akan informasi yang berkaitan dengan universitas musi rawas. Universitas Musi Rawas saat ini telah memiliki website Universitas sebagai sarana penyampaian informasi kepada mahasiswa dan masyarakat umum, perkembangan dan pemeliharaan websites tersebut terus dipantau oleh pihak Universitas untuk mengetahui sejauh mana website tersebut berhasil memenuhi kebutuhan informasi dosen dan mahasiswanya, Keberhasilan implementasi suatu Websites Universitas dapat diukur melalui persepsi dan penilaian pengguna meliputi tampilan, penyampaian informasi, dan keamanan data pengguna selama menggunakan Websites Universitas. Dari berbagai persepsi tersebut diperlukan evaluasi terhadap Websites untuk meningkatkan kualitas yang sesuai dengan kebutuhan dan fungsionalitasnya.

Oleh karena itu diperlukan analisa tentang faktor apa saja yang mempengaruhi tingkat kualitas penggunaan website, dari hasil analisa tersebut dapat dilakukan evaluasi untuk meningkatkan pemanfaatan teknologi yang diterapkan. Salah satu metode yang dapat digunakan untuk melakukan evaluasi ini adalah WebQual. Metode ini diperkenalkan oleh Stuart J. Barnes dan Ricard T. Vidgin pada tahun 2002 dan telah banyak mengalami perkembangan hingga saat ini. Metode ini menganalisa tingkat kualitas suatu website dengan menggunakan tiga area dimensi yaitu: Usability (kegunaan), Information Quality (kualitas informasi), dan Interaction Quality (kualitas interaksi).

Saat ini Universitas Musi Rawas sudah memiliki sebuah website universitas dengan alamat www.unmura.ac.id sebagai sarana penyampaian informasi kepada mahasiswa dan masyarakat umum, perkembangan dan pemeliharaan websites tersebut terus dipantau oleh pihak Universitas untuk mengetahui sejauh mana website tersebut berhasil memenuhi kebutuhan infromasi dosen dan mahasiswanya, Keberhasilan implementasi suatu Websites Universitas dapat diukur melalui persepsi dan penilaian pengguna meliputi usability, information quality, dan interaction quality dari Websites Universitas tersebut.

Dari sisi usability, tampilan pertama yang akan kita lihat pada websites www.unmura.ac.id adalah tampilan putih berpadu dengan menu berwarna hijau terang ditambah slideshow foto kegiatan universitas yang cukup besar pada tampilan atasnya, jika ditinjau dari sisi information quality, pada websites www.unmura.ac.id jika scroll kebawah maka akan terdapat tab berita yang terakhir diupdate pada tanggal 17 februari 2017 yang itu berarti berita pada websites ini terus diupdate oleh pihak universitas. Dan terakhir jika ditinjau dari sisi interaction quality, websites ini menurut penulis belum memeberikan kenyamanan pada pengguna pada website ini sudah terdapat fitur buku tamu, tetapi pengguna tidak menemukan kepastian akan fitur ini apakah diterima oleh pihak universitas atau fitur ini memiliki feedback kepada pengguna yang pasti, sehingga pengguna tidak diberikan kemudahan untuk mengekplore bentuk saran atau kritik dari pengguna untuk website ini, sehingga kedepannya dapat membangun website universitas yang lebih baik lagi. Adapun tampilan website universitas musi rawas adalah sebagai berikut.

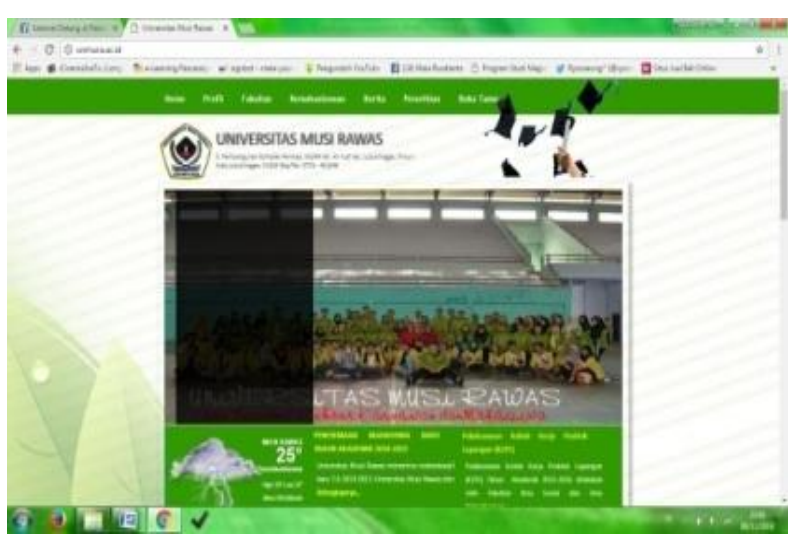

Gambar 1. Tampilan Website Unmura

\section{A. Landasan Teori}

1. Webqual

Webqual adalah pengukuran berdasarkan quality function deployment (QFD). Pengertian dari webqual adalah "Structured and disciplined process that provides a means to identify and carry the voice of the costumer through each stage of product and service development and implementation" (Slabey, 1990) dalam Budi Hermana (2009)

Beberapa Instrument pada webqual 4.0 adalah pengembangan dari beberapa versi pendahulunya yaitu webqual 1.0, webqual 2.0, dan webqual 3.0. adapun beberapa instrument penelitian yang digunakan dalam webqual 4.0 mengacu pada tabel berikut.

Tabel 1. Webqual 4.0 Instrument

\begin{tabular}{|l|l|}
\hline Category & \multicolumn{1}{|c|}{ Webqual 4.0 questions } \\
\hline Usability & $\begin{array}{l}\text { I find the site easy to learn to } \\
\text { operate } \\
\text { My interaction with the site is } \\
\text { clear and understantable }\end{array}$ \\
\hline
\end{tabular}




\begin{tabular}{|c|c|}
\hline & $\begin{array}{l}\text { Ifind the site easy to navigate } \\
\text { Ifind the site easy to use } \\
\text { The site has an attractive } \\
\text { appreance } \\
\text { The design is approriate to the } \\
\text { type of site } \\
\text { The site conveys a positive } \\
\text { experience for me } \\
\text { The site create a positive } \\
\text { experience for me }\end{array}$ \\
\hline Information quality & $\begin{array}{l}\text { Provides accurate information } \\
\text { Provides believable } \\
\text { information } \\
\text { Provides timely information } \\
\text { Provides relevant information } \\
\text { Provides easy to understand } \\
\text { information } \\
\text { Provides information at the } \\
\text { right level of detail } \\
\text { Present the information in an } \\
\text { appropriate form at }\end{array}$ \\
\hline Service Interactions & $\begin{array}{l}\text { Has a good reputation } \\
\text { It feels safe to complete } \\
\text { transactions } \\
\text { My personal information feels } \\
\text { secure } \\
\text { Creates a sense of } \\
\text { personalization } \\
\text { Conveys a sense of community } \\
\text { Makes it easy to communicate } \\
\text { with the organization } \\
\text { I feel confident that goods/ } \\
\text { services will be delivered as } \\
\text { promised }\end{array}$ \\
\hline Overall & Overall view of the web site \\
\hline
\end{tabular}

\section{B. Metode Penelitian}

Peneliti sebelum melakukan penelitian akan melakukan pendekatan yang dianggap paling cocok, yaitu sesuai dengan masalah yang akan dipecahkan. Kemudian pertimbangan lainnya adalah terletak pada masalah efisiensi, yaitu dengan mempertimbangkan keterbatasan dana, tenaga dan kemampuan dari peneliti. Dalam hal ini pendekatan (metode) penelitian yang paling baik adalah pendekatan yang paling efisien, valid dan reliable.

1. Studi Kepustakaan, untuk mempelajari teori dasar tentang analisis website menggunakan metode webqual 4.0 dari situs web, makalah, atau buku yang sudah ada.

2. Analisa dan Perancangan Sistem, mencari dan mengumpulkan data-data yang terkait analisa kualitas website ataupun pengujian kualitas website menggunakan metode webqual 4.0

\section{Pembahasan}

Uji validitas dilakukan untuk memastikan seberapa baik suatu instrumen digunakan untuk mengukur konsep yang seharusnya diukur. Rumus yang digunakan untuk menguji validitas instrumen ini adalah Product Moment dari Karl Pearson, sebagai berikut:

$$
r_{x y}=\frac{N \Sigma X Y-(\Sigma X)(\Sigma Y)}{\sqrt{\left\{N \Sigma X^{2}-(\Sigma X)^{2}\right\}\left\{N \Sigma Y^{2}-(\Sigma Y)^{2}\right\}}}
$$

Hal tersebut dilakukan dengan SPSS berdasarkan atas hasil jawaban kuesioner dari 201 responden yang menjadi sasaran dalam penelitian ini. Hasil dari uji validitas dari masing- masing dimensi pertanyaan diketahui bahwa nilai rHitung usabilityl lebih besar dari nilai rTabel yaitu sebesar 0.709, nilai rHitung Information quality1 lebih besar dari nilai rTabel yaitu sebesar 0.861, dan nilai rHitung Interaction quality1 lebih besar dari nilai rTabel yaitu sebesar 0,848 .

Dengan demikian, seluruh item instrumen dari seluruh variabel yang diamati dapat diikutsertakan dalam pengujian lebih lanjut. Untuk mengetahui apakah kuesioner tersebut reliable atau tidak, maka kuesioner tersebut diuji dengan menggunakan Metode Alpha Cronbach dengan rumus sebagai berikut

$$
r_{11}=\left[\frac{k}{k-1}\right]\left[1-\frac{\sum \sigma_{b}^{2}}{\sigma_{t}^{2}}\right]
$$

Hasil dari uji reliabilitas dengan menggunakan SPSS untuk tiap tiap pertanyaan dapat dilihat pada tabel berikut.

Tabel 3. Uji Reliabilitas

\begin{tabular}{|l|l|l|}
\hline \multicolumn{1}{|c|}{ Dimensi } & \multicolumn{1}{c|}{$\begin{array}{c}\text { Cronbach's } \\
\text { Alpha }\end{array}$} & \multicolumn{1}{c|}{ Keterangan } \\
\hline Usability & 0.797 & $\begin{array}{l}\text { Reliabilitas } \\
\text { Tinggi }\end{array}$ \\
\hline $\begin{array}{l}\text { Information } \\
\text { Quality }\end{array}$ & 0.880 & $\begin{array}{l}\text { Reliabilitas } \\
\text { Tinggi }\end{array}$ \\
\hline $\begin{array}{l}\text { Interaction } \\
\text { Quality }\end{array}$ & 0.758 & $\begin{array}{l}\text { Reliabilitas } \\
\text { Tinggi }\end{array}$ \\
\hline
\end{tabular}

Jika alpha $>0,90$ maka reliabilitas sempurna, alpha antara $0,70-0,90$ maka reliabilitas tinggi, alpha antara 0,50 - 0,70 maka reliabilitas moderat, alpha < 0,50 maka reliabilitas rendah (perry : 2004). Dari Tabel 3 didapat nilai Alpha sebesar 0.844 untuk dimensi usability, 0.846 untuk dimensi information quality, 0.833 untuk dimensi interaction quality yang menunjukkan bahwa ketiga dimensi tersebut memiliki tingkat Reliabilitas yang tinggi diatas $<0,70-0,90$.

Model Penelitian seperti yang dikembangkan dalam kerangka pemikiran, diuji tingkat kesesuaiannya dengan menggunakan kriteria goodness of fit untuk mendapatkan tingkat kesesuaiannya yang mencukupi. Hasil uji kesesuaian penelitian ini tersaji pada tabel berikut : 
Tabel 4. Evaluasi kriteria Goodness of Fit Indices Usability

\begin{tabular}{ccccc}
\hline No & $\begin{array}{c}\text { Goodness of } \\
\text { fit index }\end{array}$ & $\begin{array}{c}\text { Cut-off } \\
\text { Value }\end{array}$ & $\begin{array}{c}\text { Hasil } \\
\text { Model }\end{array}$ & Keterangan \\
\hline 1 & Probability & $<0.05$ & 0,000 & Baik \\
\hline 2 & CMIN/DF & $\leq 2.00$ & 6,343 & Tidak baik \\
\hline 3 & GFI & $\geq 0.90$ & 0,876 & Tidak baik \\
\hline 4 & AGFI & $\geq 0.90$ & 0,752 & Tidak baik \\
\hline 5 & TLI & $\geq 0.95$ & 0,798 & Tidak baik \\
\hline 6 & CFI & $\geq 0.95$ & 0,865 & Tidak baik \\
\hline 7 & RMSEA & $\leq 0.08$ & 0,163 & Tidak baik \\
\hline
\end{tabular}

Tabel 5. Evaluasi kriteria Goodness of Fit Indices Information Quality

\begin{tabular}{|c|c|c|c|c|}
\hline No & $\begin{array}{c}\text { Goodness of } \\
\text { fit index }\end{array}$ & $\begin{array}{c}\text { Cut-off } \\
\text { Value }\end{array}$ & $\begin{array}{c}\text { Hasil } \\
\text { Model }\end{array}$ & Keterangan \\
\hline 1 & Probability & $<0.05$ & 0,000 & Baik \\
\hline 2 & CMIN/DF & $\leq 2.00$ & 4,656 & Tidak baik \\
\hline 3 & GFI & $\geq 0.90$ & 0,920 & Baik \\
\hline 4 & AGFI & $\geq 0.90$ & 0,839 & Tidak baik \\
\hline 5 & TLI & $\geq 0.95$ & 0,890 & Tidak baik \\
\hline 6 & CFI & $\geq 0.95$ & 0,927 & Tidak baik \\
\hline 7 & RMSEA & $\leq 0.08$ & 0,135 & Tidak baik \\
\hline
\end{tabular}

Tabel 6. Evaluasi kriteria Goodness of Fit Indices Interaction Quality

\begin{tabular}{|c|c|c|c|c|}
\hline No & $\begin{array}{c}\text { Goodness of } \\
\text { fit index }\end{array}$ & $\begin{array}{c}\text { Cut-off } \\
\text { Value }\end{array}$ & $\begin{array}{c}\text { Hasil } \\
\text { Model }\end{array}$ & Keterangan \\
\hline 1 & Probability & $<0.05$ & 0,005 & Tidak baik \\
\hline 2 & CMIN/DF & $\leq 2.00$ & 3,315 & Tidak baik \\
\hline 3 & GFI & $\geq 0.90$ & 0,972 & Baik \\
\hline 4 & AGFI & $\geq 0.90$ & 0,915 & Baik \\
\hline 5 & TLI & $\geq 0.95$ & 0,927 & Tidak baik \\
\hline 6 & CFI & $\geq 0.95$ & 0,963 & Baik \\
\hline 7 & RMSEA & $\leq 0.08$ & 0,108 & Tidak baik \\
\hline
\end{tabular}

Struktural Equation Model Tahap Awal

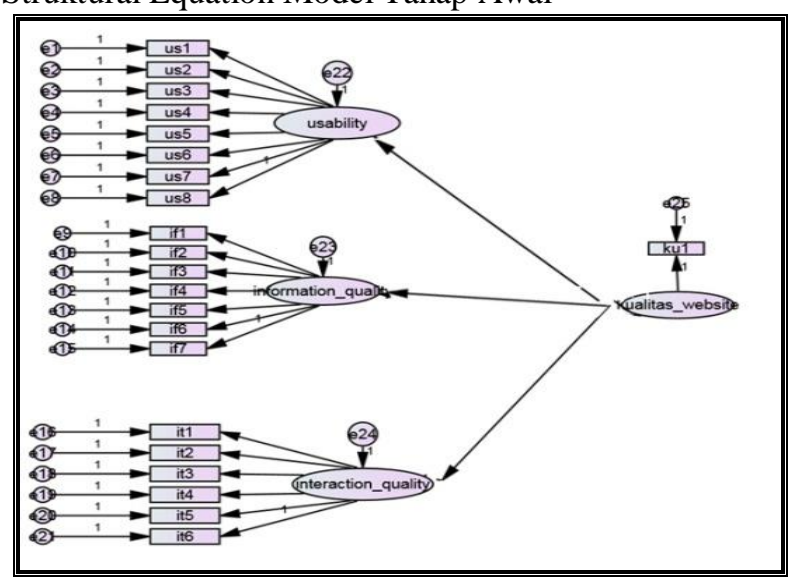

Gambar 3. Pengukuran Faktor dan Hasil Uji Model Keseluruhan variabel Tahap awal

Hasil uji konstruk pada keseluruhan variabel disajikan pada gambar 3 diatas dievaluasi berdasarkan googness of fit indices pada tabel 7 berikut dengan disajikan kriteria model serta nilai kritisnya yang memiliki kesesuaian data
Tabel 7. Evaluasi kriteria Goodness of Fit Indices untuk keseluruhan variabel tahap awal

\begin{tabular}{|c|c|c|c|c|}
\hline No & $\begin{array}{c}\text { Goodness } \\
\text { of fit index }\end{array}$ & $\begin{array}{c}\text { Cut- } \\
\text { off } \\
\text { Value }\end{array}$ & $\begin{array}{c}\text { Hasil } \\
\text { Model }\end{array}$ & Keterangan \\
\hline 1 & Probability & $<0.05$ & 0,000 & Baik \\
\hline 2 & CMIN/DF & $\leq 2.00$ & 1,813 & Baik \\
\hline 3 & GFI & $\geq 0.90$ & 0,849 & Tidak baik \\
\hline 4 & AGFI & $\geq 0.90$ & 0,815 & Tidak baik \\
\hline 5 & TLI & $\geq 0.95$ & 0,896 & Tidak baik \\
\hline 6 & CFI & $\geq 0.95$ & 0,908 & Tidak baik \\
\hline 7 & RMSEA & $\leq 0.08$ & 0,064 & Baik \\
\hline
\end{tabular}

Dari evaluasi model yang diajukan menunjukkan bahwa evaluasi model terhadap konstruk secara keseluruhan menghasilkan nilai diatas kritis yang menunjukkan bahwa model telah sesuai dengan data, sehingga dapat dilakukan uji kesesuaian model selanjutnya.

Tabel 8. Loading Factor Usability, Information quality, Interaction Quality Tahap Awal

\begin{tabular}{|c|c|c|c|}
\hline No & Indikator & $\begin{array}{c}\text { Loading } \\
\text { Factor }\end{array}$ & Keterangan \\
\hline 1 & Us1 & 0,61 & Fix \\
\hline 2 & Us2 & 0,45 & Fix \\
\hline 3 & Us3 & 0,90 & Fix \\
\hline 4 & Us4 & 0,89 & Fix \\
\hline 5 & Us5 & 0,53 & Fix \\
\hline 6 & Us6 & 0,44 & Fix \\
\hline 7 & Us7 & 0,58 & Fix \\
\hline 8 & Us8 & 0,04 & Tidak \\
& & & Signifikan \\
\hline 9 & If1 & 0,83 & Fix \\
\hline 10 & If2 & 0,64 & Fix \\
\hline 11 & If3 & 0,63 & Fix \\
\hline 12 & If4 & 0,77 & Fix \\
\hline 13 & If5 & 0,54 & Fix \\
\hline 14 & If6 & 0,80 & Fix \\
\hline 15 & If7 & 0,82 & Fix \\
\hline 16 & It1 & 0,63 & Fix \\
\hline 17 & It2 & 0,77 & Fix \\
\hline 18 & It3 & 0,72 & Fix \\
\hline 19 & It4 & 0,68 & Fix \\
\hline 20 & It5 & 0,66 & Fix \\
\hline 21 & It6 & 0,11 & Tidak \\
& & & Signifikan \\
\hline
\end{tabular}

Berdasarkan fakta empiris pada tabel 8 dapat dikata bahwa faktor loading pada indikator Us8 dan It6 lebih rendah dari nilai yang direkomendasikan $(<0.4)$ (Ferdinand, 2002), oleh karena itu indikator Us8 dan It6 dihapus dari model pengukuran. Model ini akan diuji ulang setelah menghapus Us8 dan It6.

Struktural Equation Model Tahap Akhir 


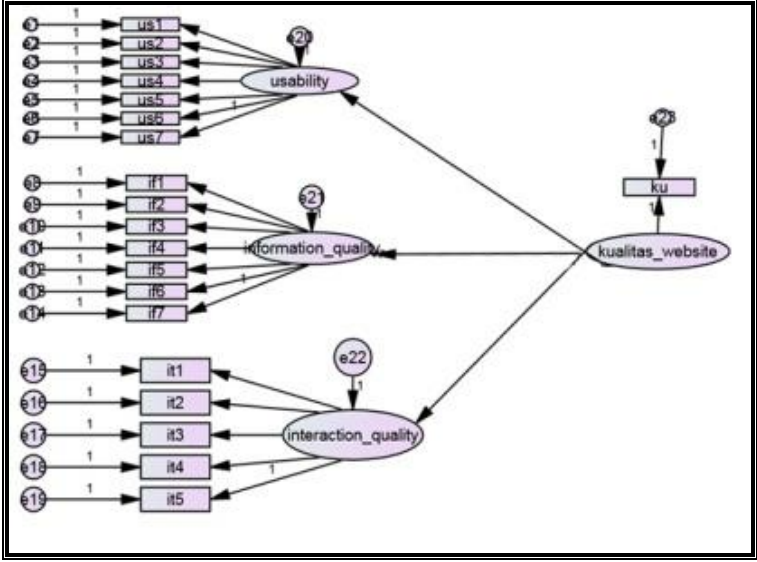

Gambar 4. Pengukuran Faktor dan Hasil Uji Model Keseluruhan variabel Tahap akhir

sil uji konstruk pada keseluruhan variabel disajikan pada gambar 4 diatas dievaluasi berdasarkan googness of fit indices pada tabel 9 berikut dengan disajikan kriteria model serta nilai kritisnya yang memiliki kesesuaian data

Tabel 9. Evaluasi kriteria Goodness of Fit Indices untuk keseluruhan variabel tahap akhir

\begin{tabular}{|c|c|c|c|c|}
\hline No & $\begin{array}{c}\text { Goodness } \\
\text { offit } \\
\text { index }\end{array}$ & $\begin{array}{c}\text { Cut-off } \\
\text { Value }\end{array}$ & $\begin{array}{c}\text { Hasil } \\
\text { Model }\end{array}$ & Keterangan \\
\hline 1 & Probability & $<0.05$ & 0,000 & Baik \\
\hline 2 & CMIN/DF & $\leq 2.00$ & 1,878 & Baik \\
\hline 3 & GFI & $\geq 0.90$ & 0,862 & Tidak baik \\
\hline 4 & AGFI & $\geq 0.90$ & 0,826 & Tidak baik \\
\hline 5 & TLI & $\geq 0.95$ & 0,907 & Tidak baik \\
\hline 6 & CFI & $\geq 0.95$ & 0,918 & Tidak baik \\
\hline 7 & RMSEA & $\leq 0.08$ & 0,066 & Baik \\
\hline
\end{tabular}

Dari evaluasi model yang diajukan menunjukkan bahwa evaluasi model terhadap konstruk secara keseluruhan menghasilkan nilai diatas kritis yang menunjukkan bahwa model telah sesuai dengan data, sehingga dapat dilakukan uji kesesuaian model selanjutnya.

Tabel 10. Loading Factor Usability, Information quality, Interaction Quality Tahap Akhir

\begin{tabular}{|c|c|c|c|}
\hline No & Indikator & $\begin{array}{c}\text { Loading } \\
\text { Factor }\end{array}$ & Keterangan \\
\hline 1 & Us1 & 0,61 & Fix \\
\hline 2 & Us2 & 0,45 & Fix \\
\hline 3 & Us3 & 0,90 & Fix \\
\hline 4 & Us4 & 0,89 & Fix \\
\hline 5 & Us5 & 0,53 & Fix \\
\hline 6 & Us6 & 0,44 & Fix \\
\hline 7 & Us7 & 0,58 & Fix \\
\hline 8 & If1 & 0,83 & Fix \\
\hline 9 & If2 & 0,64 & Fix \\
\hline 10 & If3 & 0,63 & Fix \\
\hline 11 & If4 & 0,77 & Fix \\
\hline 12 & If5 & 0,54 & Fix \\
\hline
\end{tabular}

\begin{tabular}{|l|l|l|l|}
\hline 13 & If6 & 0,80 & Fix \\
\hline 14 & If7 & 0,82 & Fix \\
\hline 15 & It & 0,63 & Fix \\
\hline 16 & It2 & 0,77 & Fix \\
\hline 17 & It3 & 0,72 & Fix \\
\hline 18 & It4 & 0,68 & Fix \\
\hline 19 & It5 & 0,66 & Fix \\
\hline
\end{tabular}

Berdasarkan fakta empiris seperti pada tabel 10 dapat dikatakan keseluruhan indikator sebagai pengukur variabel Usability, Information Quality, Intraction Quality bersifat pasti (Fix).

\section{Kesimpulan}

Berdasarkan hasil penelitian, peneliti menarik kesimpulan berkaitan dengan kualitas website universitas musi rawas antara lain :

Faktor usability memiliki nilai rata rata yang paling besar dibanding faktor information quality, dan interaction quality yaitu pada skala 2,89 yang berada diantara 2,50 - 5 yang artinya faktor usability pada website universitas musi rawas dinyatakan cukup baik dan memadai.

Faktor information quality memiliki nilai rata rata pada skala 2,733 yang berada diantara 2,50 - 5 yang artinya faktor information quality pada website universitas musi rawas dinyatakan cukup baik dan memadai.

Faktor interaction quality memiliki nilai rata rata pada skala 2,459 yang berada diantara 0 - 2,50 yang artinya faktor interaction quality pada website universitas musi rawas dinyatakan belum cukup baik dan memadai.

Uji reliabilitas yang menyatakan information quality memiliki nilai alpha cronbach yang paling besar dibanding faktor usabilty, dan interaction quality yaitu sebesar 0,880 sedangkan faktor usability sebesar 0.797 dan faktor interaction quality sebesar 0,758 yang artinya variabel bersifat reliabel, penelitian bersifat valid dan penelitian dapat diterima.

\section{Saran}

Berdasarkan pembahasan pada bab bab sebelumnya masih terdapat beberapa point yang masih perlu diperbaiki karena nilainya masih kurang bila dibangdingkan dengan nilai yang lainnya, seperti pada dimensi usability terdapat point pertanyaan no 8 yaitu "Website http://unmura.ac.id/ memberikan pengalaman positif?" yang berarti pihak universitas perlu memperbaiki website universitas agar websites lebih dapat menarik minat pengunjung dan membuat pengunjung betah mengunjungi website tersebut. Dan pada dimensi Interaction quality terdapat pada point pertanyaan no 6 yaitu "Menurut anda http://unmura.ac.id/ memberikan layanan sesuai dengan apa yang disajikan?" yang itu berarti pihak universitas perlu memberikan pelayanan yang lebih terhadap website universitas. 


\section{DaftarPustaka}

Barnes, j. \& Vidgen, r. 2003, Measuring Website Quality Improvement: A Case study of the Forum on Strategic management knowledge exchange, New York: Industrial management \& Data System,

Fajar, Z, 2014, 'Analisis Kualitas Layanan Website Btkp-Diy Menggunakan Metode Webqual 4.0', Jurnal JARKOM Vol. 1 No. 2

Irawan, C, 2012, 'Evaluasi Kualitas Website Pemerintah Daerah Dengan Menggunakan Webqual (Studi Kasus Pada Kabupaten Ogan Ilir)‘, Jurnal Sistem Informasi (JSI), VOL. 4, NO. 2

Sastika, w, 2016, 'Analisis Pengaruh Kualitas Website (Webqual 4.0) Terhadap Keputusan Pembelian Pada Website E-Commerce Traveloka', Jurnal Seminar Nasional Teknologi Informasi dan Komunikasi 2016

Setiyorini, a, 2016, 'Analisa Pengukuran Kualitas Layanan Website Fakultas Teknik Universitas Janabadra Mengunakan Metode Webqual', Jurnal Informasi Intrekatif Vol. 1 No. 1

Syaifullah, 2016, 'Pengukuran Kualitas Website Menggunakan Metode Webqual 4.0‘, Jurnal Rekayasa dan Manajemen Sistem Informasi, Vol. 2 